\title{
ASSESSING AND TRACKING THE FACTORS INFLUENCING STUDENT WELLBEING IN FIRST-YEAR ENGINEERING
}

\author{
Quentin A. Golsteyn, Peter M. Ostafichuk \\ University of British Columbia \\ ostafichuk@mech.ubc.ca
}

\begin{abstract}
In recent years, there has been increasing awareness surrounding student wellbeing. The first year of university can be difficult due to the change in expectations and responsibilities associated with this transition. As many of the resources offered to support students are accessible on a voluntary basis, their effectiveness largely depends on their level of usage. Within the first year of the $U B C$ Engineering program, we implemented four interventions looking at identifying potential challenges faced by students, and the resources they see as available.

We based our work on a model that represents wellbeing as the balance between challenges and resources. We found that academics are a significant point of focus for students, with grades, second-year placement, and workload making $40 \%$ of the stressors throughout the academic year. In addition, discrepancies in academic background and the importance of having a routine were additional themes mentioned by students. COVID-19 was found to have a small impact on student wellbeing, most likely driven by the rapid transition away from student residences and uncertainty caused by the changes in the university's grading policy. Students had difficulty finding specific resources that could support them throughout the year. Having more opportunities for studying with peers, and having access to what of upper-year students were requested by first-year students.
\end{abstract}

Keywords: First-year engineering, university transition, resources and challenges, wellness and wellbeing

\section{INTRODUCTION}

The transition to university can be a time of high stress for first-year students. It comes with changes in identity, responsibility, and social contacts. The format of courses usually differs from that of high-school, by instructional methods, assessment techniques, and teacher and peer relationships. [1]

In recent years, there has been an increased interest in mental health concerns and counselling usage at Canadian universities. [2] Engineering faculties have also started looking at mental health and wellbeing in the context of their programs. A 2017 survey by the University of British
Columbia (UBC) Engineering Undergraduate Society found that in the 12 months prior, $79 \%$ of students surveyed experienced feeling exhausted, and $42 \%$ of students experienced feeling hopeless. [3]

\subsection{Defining wellbeing}

According to the World Health Organization, wellbeing, or wellness, is defined as the state "in which every individual realizes his or her own potential, can cope with the normal stresses of life, can work productively and fruitfully, and is able to make a contribution to her or his community." [4]

Whereas the outcomes of wellbeing can be observedgood social connectedness, life satisfaction, positive emotions - defining the general constructs that lead to positive wellbeing is challenging. Individuals bring their own experiences that may affect what they consider positive wellbeing. Gender, country of origin, and beliefs may all affect how individuals see the world around them, and how they respond to it.

To guide this study, we selected a model that represents wellbeing as the balance between an individual's resources and the challenges they face. [5] Under this model, stable wellbeing is "when individuals have the psychological, social, and physical resources they need to meet a particular psychological, social, and/or physical challenge," depicted as a "see-saw" (Fig. 1). On one end of this "see-saw" are the resources that an individual has in their possession, and on the other end, the challenges they face.

The see-saw remains stable and centred if the individual has the resources to cope with the challenges at hand. Too many challenges, and the see-saw tips one way, representing feelings of being overwhelmed; too few challenges, and the see-saw tips in the other direction, representing feelings of stagnation.

The assumption at the root of the interventions described in this paper is that by describing the challenges and resources intrinsic to the first year of university, we can begin to identify possible areas causing a positive or negative impact on student wellbeing. 


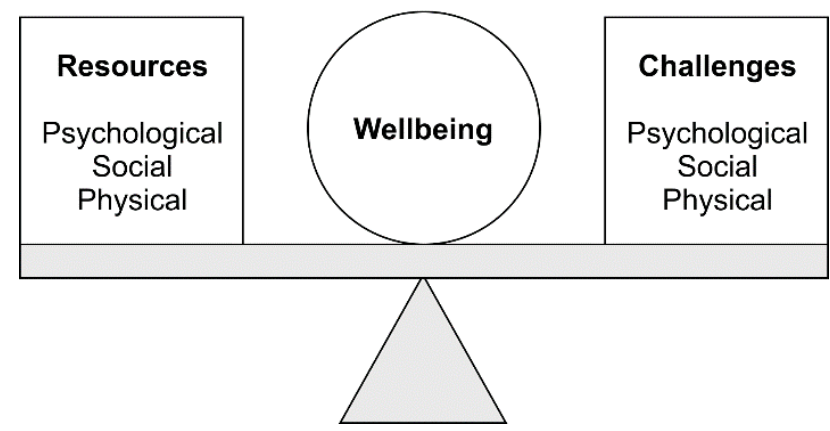

Fig. 1. The wellbeing see-saw [5]

\subsection{Motivation}

This study looks at identifying areas that could lead to improvements in student wellbeing within the scope of the first-year engineering program at UBC, although the results are applicable to any Canadian university. The first year of the UBC Engineering program is considered a critical time for students, and a number of initiatives are offered to help students navigate this time.

As many of the resources offered to students are accessible on a voluntary basis, their effectiveness largely depends on their level of usage. Based on anecdotal feedback from advising staff and student leaders, a discrepancy exists between the need to support students with their wellbeing and the perceived apathy from the student population to utilize the resources available to them. Understanding the students' perspective, particularly the challenges students face and the resource they see as accessible could prove valuable in creating more effective initiatives targeted at improving student wellbeing.

\section{CONTEXT}

The studies and interventions described in this paper were conducted in the first-year engineering program at UBC. This program has an annual intake of between 800 and 1000 students into a common curriculum. Entry into a second-year engineering program (e.g. civil, electrical, mechanical, etc.) is done competitively at the end of firstyear, with first-year GPA used as the primary ranking factor. Many programs also consider a written personal statement and other factors when determining which students to accept.

The majority of courses in the first year at UBC consist of foundational math and science, but all students take an introduction to engineering course (APSC 100) in the fall term, and the majority of students also take a follow-up course (APSC 101) in the spring term that expands on the topics from the first course. These courses are taught in a team-focused and flipped classroom format, with two 50minute active learning lectures each week and one 110minute studio. [6] These courses, and the studios in particular, were used to deliver a number of the interventions and studies described in this paper.

\section{METHODS}

Four interventions of varying scale were conducted during the 2018-2019 and the 2019-2020 academic year.

During the 2018-2019 academic year, we conducted two interventions. The first was a classroom intervention to identify general categories of "successes" and "challenges" faced by students during the first year of their undergraduate engineering degree. This was followed by a survey later in the academic year to further determine key factors influencing the first-year experience and to identify opportunity gaps.

During the 2019-2020 academic year, two additional interventions were organized to provide additional context to the factors we identified the year prior. We recruited 30 first-year student representatives to provide weekly feedback on the ongoing academic year. In parallel, we reached out to the class as a whole via a survey, rotating each week to a different quarter of the first-year cohort, asking students to indicate their level of wellbeing using the Short Warwick-Edinburgh wellbeing scale.

Each of the four interventions is described in detail in Sections 3.1 to 3.4.

\subsection{Mapping "successes" and "challenges"}

An in-class activity was conducted in the APSC 100 studio sessions over a one-week period during the month of October 2018. The goal of this activity was to capture what students considered to be their most significant success and their most difficult challenge since starting university. The activity was moderated by a staff member from the faculty's advising office. Students wrote their responses to each of the prompts on sticky notes.

Within the APSC 100 studios, students work in persistent teams of nominally five or six members. This activity benefited from the use of small, preexisting teams to increase comfort level in sharing personal experiences with others. The hope was also to start building relationships with staff advisors who could better assess the progress and effectiveness of the activity.

The student responses were digitized and coded to create a list of factors influencing the initial months of their first-year experience. These results were shared with students through the APSC 100 course website. Factors were then sorted by opportunity scores (described further in the next section) and areas of concern for future initiatives were identified.

\subsection{Identifying opportunity gaps}

Using the factors identified in the first activity, a survey was created to identify factors that presented the most significant "opportunity" for faculty intervention. This 
survey was distributed during the month of March 2019 through the APSC 101 course website.

The survey was developed using the opportunity algorithm, which asks respondents to report the level of importance and satisfaction that a particular factor has on them. [7] Importance and satisfaction were recorded using a 5-point scale (not all important / very dissatisfied, slightly important / dissatisfied, moderately important / neutral, very important / satisfied, extremely important / very satisfied). The percentage of respondents selecting the toptwo boxes for the two attributes was measured, and an opportunity score was calculated from this measure using the following formula:

Opportunity score $=I+\max (I-S, 0)$.

Here, I and S are the top-box percentages for importance and satisfaction, respectively. A high opportunity score indicates an area of high importance but low satisfaction, which could potentially benefit from faculty support.

As the number of factors identified was very large, respondents were given a random assortment of 20 factors when completing the survey to prevent survey fatigue. Participation in the survey was voluntary but was incentivized through a random draw of ten $\$ 10$ Starbucks gift cards.

\subsection{Tracking wellbeing factors over the course of an academic year}

To understand how students' perspectives on their wellbeing shift during the academic year, a series of short (under two minute) surveys were developed and distributed weekly via email during the 2019-2020 academic year. The first-year cohort was divided into four groups, and the group invited to complete the survey was rotated each week (i.e., each student received a survey invite every four weeks, for a total of three invites per term). This approach was implemented to limit survey fatigue. Participation in the survey was voluntary and no incentive was provided.

This survey asked students to rank topics that were the most challenging to them the prior week, complete the Short Warwick-Edinburgh wellbeing questionnaire, [7] and write a word that described how they felt currently.

The Short Warwick-Edinburgh wellbeing questionnaire consists of seven questions as follows:

1. I've been feeling optimistic about the future

2. I've been feeling useful

3. I've been feeling relaxed

4. I've been dealing with problems well

5. I've been thinking clearly

6. I've been feeling close to other people

7. I've been able to make up my own mind about things Students are asked to indicate the frequency with which each statement applied using a 5-point scale (none of the time, rarely, some of the time, often, all of the time). The mean score was measured.

\subsection{Collecting weekly feedback from student representatives}

To provide context to the responses we received via the weekly class-wide surveys, 30 student representatives were recruited at the start of the 2019-2020 academic year. Each week, they answered 4 open-ended questions, as follows:

1 . What are you proud of this week?

2. What was challenging about this week?

3. Are there any resources you wish you had this week?

4. Please share any feedback you have or have received from other students.

At the end of the first semester, student representatives were invited to attend a 90-minute focus group on their experience in university up to this point. Two focus groups were held, with 6 students attending each session.

\section{RESULTS}

\subsection{Mapping "successes" and "challenges" in first- year engineering}

In total, 629 students participated in the initial mapping exercise, or $62 \%$ of the total enrolled student population in APSC 100 at the time.

After the initial analysis of the data, it appeared that some successes were also considered challenges by other students. Hence, they were grouped to form factors. The first activity generated 74 unique factors, inclusive of all recorded successes and challenges. These factors were further divided into 6 categories:

1. academic and professional development,

2. social,

3. wellbeing,

4. workload,

5. lifestyle, and

6. cultural integration.

Example of factors associated with each category can be found in Appendix A.

\subsection{Calculating opportunity scores}

The survey that was built from the mapping exercise outcomes was completed by 108 students, or $13 \%$ of the total enrolled student population in APSC 101 at the time. As respondents only completed a fraction of the factors included in the survey, the response rate for each factor is lower, averaging around 35 responses per factor.

Academic and wellness factors had higher opportunity scores than other categories of factors (Fig. 2). Recall, a high opportunity score is linked high importance but low satisfaction. The ten factors with the highest opportunity scores can be found in Table 1 . 


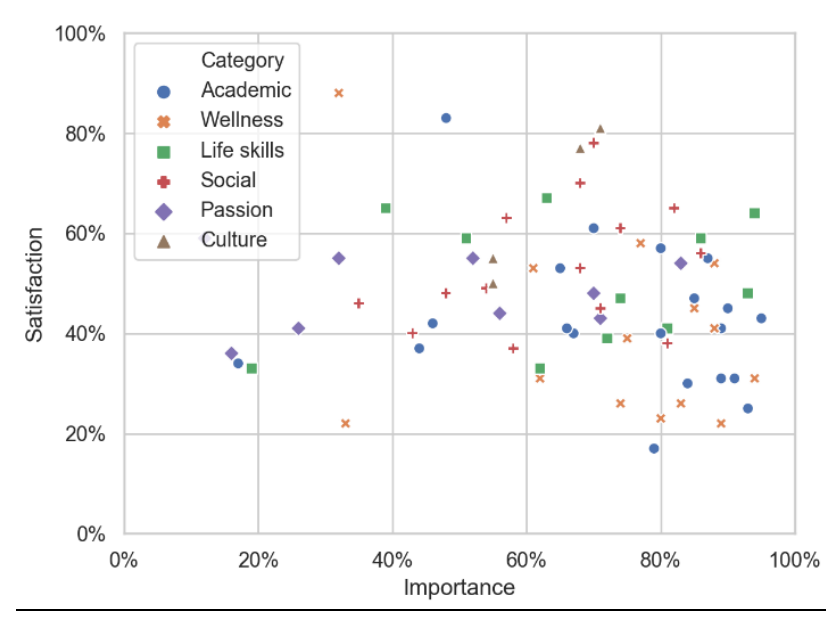

Fig. 2. Satisfaction versus Importance Scatterplot

Table 1. Factors with High Opportunity Score (I = importance, $\%, \mathrm{~S}=$ satisfaction, $\%, \mathrm{O}=$ opportunity score)

\begin{tabular}{lccc}
\hline Factor & I & S & O \\
\hline Overcoming the fear of failure & 93 & 25 & 1.61 \\
\hline Feeling positive throughout the year & 94 & 31 & 1.57 \\
\hline Getting enough sleep & 89 & 22 & 1.57 \\
\hline Having enough time to study for exams & 91 & 31 & 1.50 \\
\hline Handling the course load & 95 & 43 & 1.48 \\
\hline Being more productive & 89 & 31 & 1.46 \\
\hline Avoiding procrastination & 79 & 17 & 1.41 \\
\hline Dealing with feeling overwhelmed & 83 & 26 & 1.40 \\
\hline $\begin{array}{l}\text { Balancing time between homework and } \\
\text { studying for midterms/finals }\end{array}$ & 84 & \multirow{2}{*}{30} & 1.38 \\
\hline $\begin{array}{l}\text { Having enough time to complete } \\
\text { homework }\end{array}$ & 89 & \multirow{2}{*}{41} & 1.38 \\
\hline
\end{tabular}

\subsection{Tracking wellbeing factors over the course of an academic year}

The participation in the weekly surveys conducted in 2019-2020 averaged 128 students per week in Term 1 (from a low of 64 participants to a high of 224) but dropped to an average of 27 in Term 2 (from a low of 11 to a high of 56). The variation in participation from week to week appeared to be most strongly related to the particular group of students, as it followed a four-week cycle rather than a general trend through the term. The reasons for the large reduction in participation from Term 1 to Term 2 are unclear but may be related to general apathy to additional surveys as the academic year progresses.

As shown in Fig. 3, there was a slight trend in decreasing wellbeing reported by students over the academic year. Adopting a 0-4 scale, the average WEMWBS rating was about 2.5 at the beginning of Term 1 , and this gradually diminished to an average of about 2.0 by the end of Term 2. Students consistently rated being able to "make up their own mind" highest almost every week, and "feeling relaxed" as lowest. The drop in average wellbeing in weeks 4 and 5 of Term 2 coincide with a major project deliverable in the APSC 101 course. Interestingly, the cancelation of in-person classes due to COVID-19 (occurring after Week 10 in Term 2) only appeared to have a minor impact on student-reported wellbeing. That is not to say there were no impacts: the "feeling close to other people" criterion, which was the highest-rated criterion in Week 6, dropped to the lowest-rated criterion in Week 15, during the final exam period, likely due at least in part to the impacts of social distancing.

The survey responses tracking the topics of greatest concern to students is shown in Fig. 4 as a stacked bar graph. To create this chart, each student's top-ranked concern was given 5 points, their second-ranked was given 4 points, and so on, and the chart shows the relative points for each option. Obtaining high grades and being able to get into their preferred second-year program (recall, second-year program placement is competitive at UBC) accounted for roughly $40 \%$ of the stressors. A noticeable decrease in the frequency of "workload" occurred in both terms during the final-exam periods. With the shift to online instruction, there were only minor changes (if any) in living on one's own, being away from family, maintaining relationships, or making friends. There was a spike in "other" concerns immediately before and after the shift to online learning; almost all of the descriptive text associated with this choice related to COVID-19 or the changes it brought.

\subsection{Collecting weekly feedback from student representatives}

While initially, all student representatives (30 students) submitted their weekly feedback, 10 students continued to fill out the weekly survey by the end of the academic year, with a sharp decrease in participation at the start of the second semester.

Topics covered by students in their weekly response and the focus groups fell in these four categories:

1. Academics: examinations and projects, academic performance, handling the course-load, second-year placement.

2. Discrepancies in academic knowledge: students with programming experience vs. no programming experience, students with calculus vs. no knowledge of calculus.

3. Time management: balancing academics, extracurriculars, social life, and personal life.

4. Developing habits and routines: being to maintain a regular schedule. 


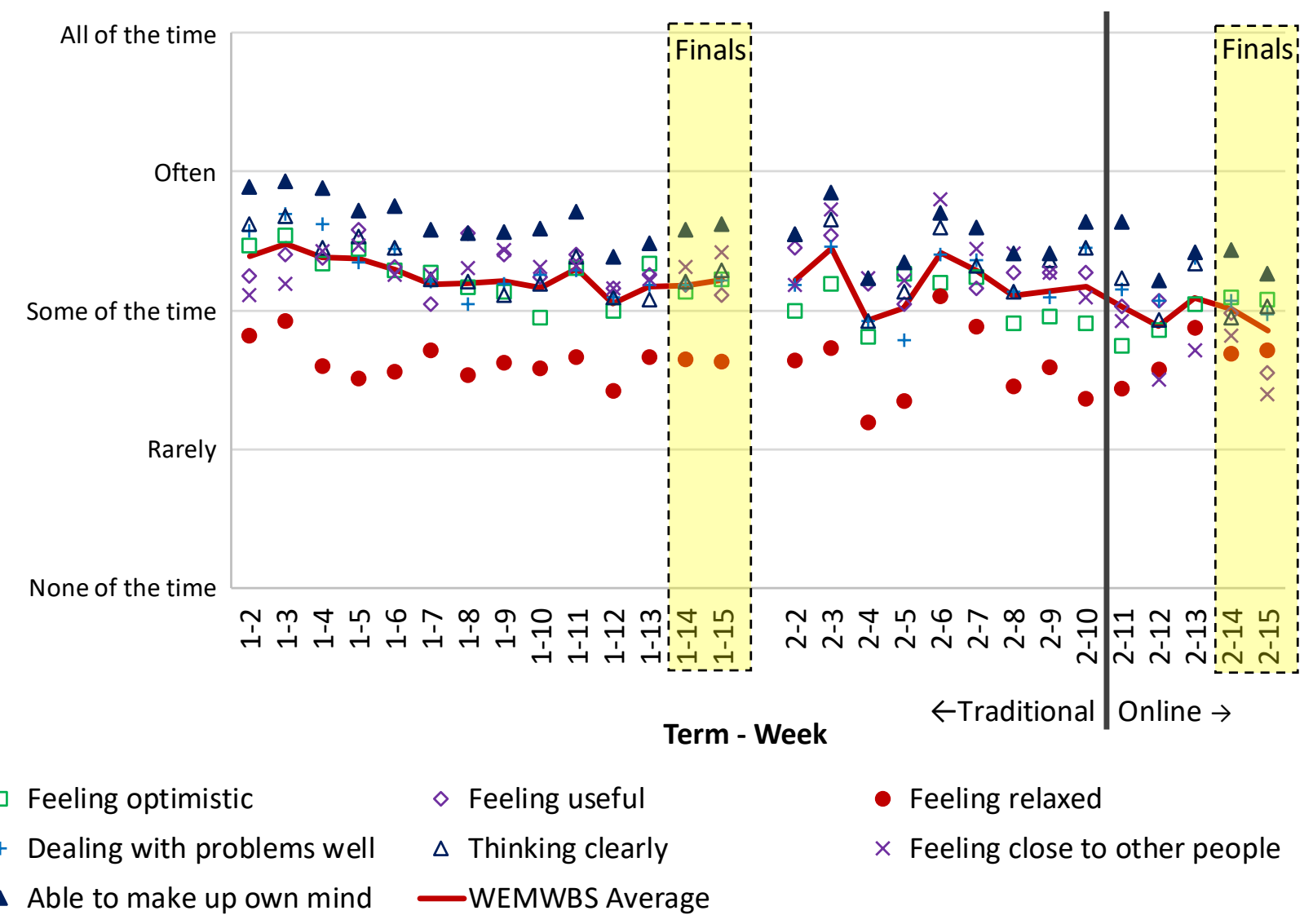

Fig. 3. Change in WEMWBS survey responses by week

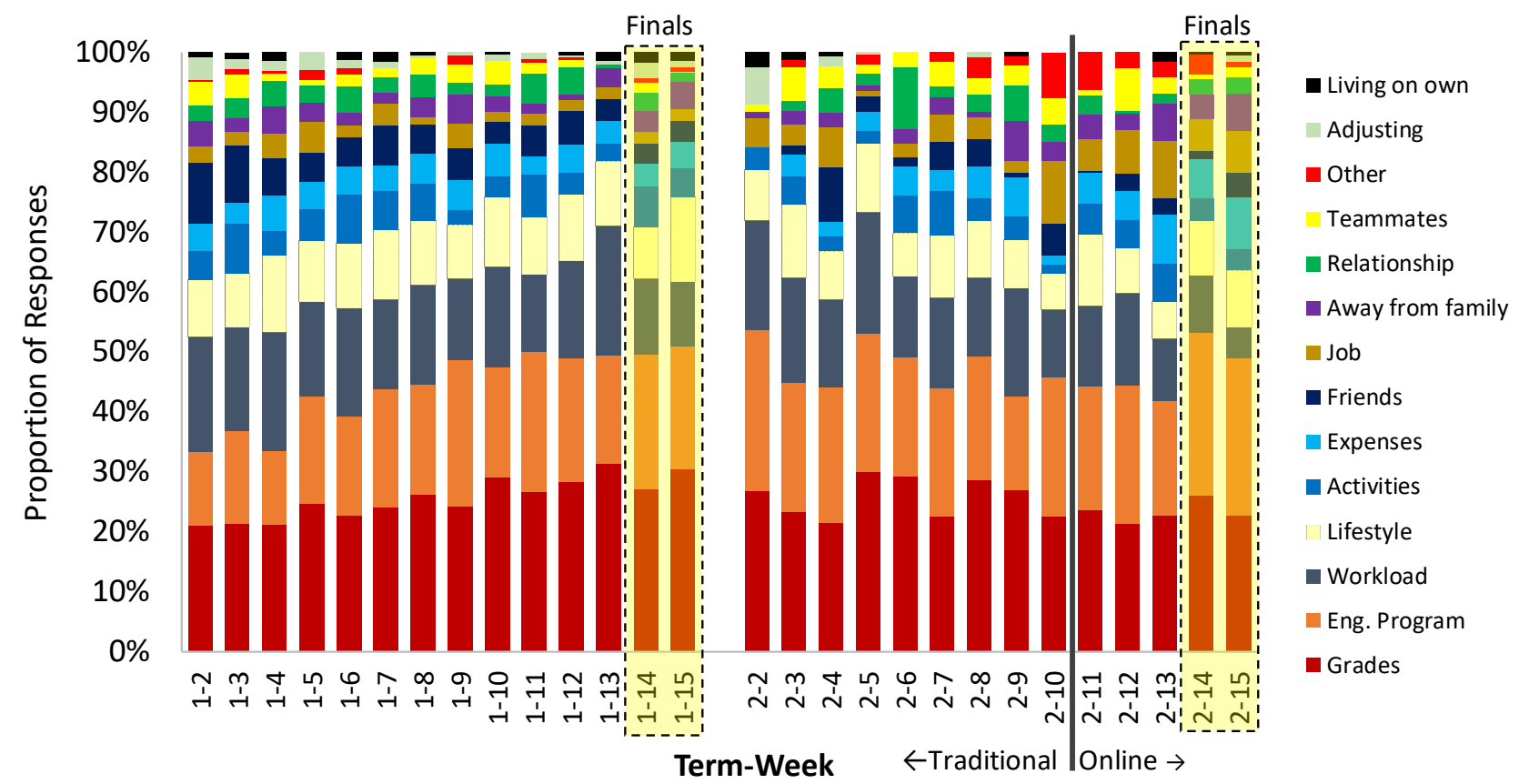

Fig. 4. Student reported stressors from the weekly course survey 
Some students requested resources on how to adequately prepare for an examination, accessing additional practice problems, having more opportunities for study sessions, learn to adapt following poor academic results, or handle the stress and anxiety associated with academic examinations or homework. Students also wished to have access to upper-year students to learn more about their second-year program of interest and learn about best practices to succeed in university. Many students, however, could not name specific resources they saw as potentially beneficial. Many responses had the question blank or indicated that no resources could help them at the moment.

The cancellation of in-person classes due to COVID-19 had an impact on the weekly responses. As students had the opportunity to leave their first-year residences to return home, all student representatives indicated having left by the end of March. During that time, students indicated having difficulty keeping up with classes while having to move out of residences. As the transition came abruptly, many students did not have the chance to say goodbye to their friends. Following the transition to online classes, students mentioned having adapted to this new normal. Still, the change in the university grading policies, and its potential on the competitive second-year placement process was a source of concern until the end of the academic year.

\section{DISCUSSION}

\subsection{The importance of academics}

Academics appeared to be a primary source of concern for students. If student representatives were not discussing academics directly in their responses, then academics were usually incidental to the matter at hand (for example, having little sleep due to a high academic workload, or talking about their stress due to an upcoming examination). Seven of the top ten factors by opportunity scores were academics-related. The weekly surveys showed that grades and second-year placement were consistently ranked as a primary source of concern for students week after week, and accounted for $40 \%$ of the stressors.

Curiously, in comparison, factors typically emphasized in university orientations (including making friends, adjusting to life on campus, being away from family and home, and living on their own) were not primary concerns in our surveys. (To be clear, we are not suggesting these are not important to include in resources and orientation, only that they are not top of mind for engineering students at UBC.)

This highlights the importance academics may have on a student's wellbeing at this stage of a student's academic career. It is echoed in the literature, whereas it was found that $80 \%$ of students base their self-worth on academic performance. [9] In addition, it is important to remember that second-year placement is competitive, with first-year GPA used as the primary ranking factor.

\subsection{Discrepancies in prior academic experiences}

Student representatives mentioned that students do not share the same academic experience prior to their entry into first-year engineering. For example, APSC 160: Introduction to Programming, a mandatory first-year course, was harder for those who did not have prior programming experience. Some students had done Calculus in high-school, while others did not. In addition, some students came from an International Baccalaureate (IB) or similar elective programs. Students mentioned that these programs helped them prepare for the workload of the first-year program and for learning the material covered in the university introductory physics, mathematics, and chemistry courses.

Ultimately, student representatives agreed that firstyear engineering was not an "even playing field" and that the challenges students face in the program could be associated with their high-school background.

\subsection{Workload, breaks, and routines}

During the first semester, students mentioned seeing the workload increase progressively as the weeks passed, with a peak in workload during midterm season. Workload remained one of the top stressors throughout the academic year. A factor that was raised as a challenge early on by students was the ability to balance working on homework and projects while simultaneously studying for midterms.

The weekly surveys highlight concerns relating to a lack of feelings of relaxation. When asked during the focus groups if students are proactive in taking breaks, students disagreed mentioned sometimes feeling guilty taking time off. "When midterms are happening, people are just stressed all the time. So they would feel guilty to take some 'me time' during the day, even if they are not studying. They won't be doing anything else, they will just be stressed. Floating in that stress." Many agreed that academics were constantly top of mind for them. Students also mentioned having long days, some indicated starting classes at 8 am and only returning home after $9 \mathrm{pm}$.

Routines were identified as important to student wellbeing and success. "I have heard a lot of people talk about how they want to have a schedule for how they fit everything into their lives, especially as first-year is more difficult than high school. A big goal for the people I have talked to is to come up with a schedule they can commit to so that they can do as much as possible along with school." Students mentioned they found it difficult to maintain a schedule or routine due to the increased workload of university. Many agreed they had to shift their focus from hobbies and extra-curricular involvements to academics. 


\subsection{Access to university services and other resources}

More study material or study opportunities were often requested by student representatives; however, beyond academics, students had difficulty naming any resource they saw as beneficial to them, including resources already offered by the university.

When asked why students have difficulty naming resources during the focus groups, a student mentioned: "I feel that I have all the resources, I am not using them properly." Students listed apathy, not being sure what the resource would do to help them, and the possibility that a resource does not ultimately help them as reasons why they would not access it. For example, when discussing the benefits of office hours, a student said: "I tried to go to office hours, but I didn't feel any improvements. I didn't feel that I understand the professor more than after lecture."

Stigma was also mentioned, particularly around mental health and wellbeing resources, including counselling. "[Students] keep it to themselves. It's the stigma that's the problem. Take the connotation of going to a counsellor, it feels like going to a doctor."

Having more opportunities to interact with other students, particularly upper-year students, was mentioned in student representative responses and during the focus groups. Students wished they could have more opportunities for study groups, have access to an online forum such as Piazza, [10] and have the possibility to talk to upper-year students to learn more about their programs.

\subsection{The expectations of university}

In general, the factors and the student representative responses were found to fit two general categories. They either discussed a topic related to university expectations (knowing what to expect regarding an assignment or examination, second-year placement requirements, understand course content and outcome) or maintaining or developing habits and routines to meet these university expectations (improving study skills, time management, prioritizing).

We found particularly striking that fear of failure received the highest opportunity score, highlighting the possibility that uncertainty may be a significant challenge for students. "Overall I think we are looking for some guidance." This was the final remark a student had during a focus group session, which the other members agreed to.

These themes were highlighted in the book, Helping and Supporting Students, discussing the role universities play in supporting first-year students in their transition to university. The author echoes the themes above, that the transition to university for students could be a process of understanding the expectations of the university environment and negotiating a pattern of behaviours that is consistent with these expectations. [11, p. 42]

\section{CONCLUSION}

Using a model defining wellbeing as the balance between challenges and resources, we designed four interventions aimed at determining the challenges faced by students, and the resources they see as accessible.

- 74 factors were identified, centred on academics, wellbeing, social, workload, lifestyle, and cultural integration. Academic and wellbeing factors received the highest opportunity scores.

- The weekly surveys suggested there was a small, gradual deterioration in student wellbeing throughout the academic year.

- The weekly surveys suggest favourable student perceptions about their capacity to make up their own mind but highlight concerns relating to a lack of feelings of relaxation.

- Tracking student stressors week to week reveals grades, getting into the second-year program of choice, and workload as the most significant concerns.

- The impact of COVID-19 and the shift to online learning at the end of Term 2 appears to have a small, negative impact on student wellbeing.

- Student representatives discussed academics, discrepancies, time management, and developing new habits and routines.

- In general, we found that students were largely focused on their academics, with additional concerns regarding a potential imbalance in prior academic experience, and workload and the importance of routines. Students had difficulty naming resources that they saw as potentially beneficial to their success.

- We ultimately believe that the first-year transition is shaped by a need to understand university expectations and negotiating a pattern of behaviour that is consistent with these expectations.

\section{Acknowledgements}

We would like to thank the first-year student representatives who volunteered their time for this project. We would also like to thank Mimi Tse (First-Year Student Coordinator), Amy Vozal (Undergraduate Student Advisor), and the UBC Engineering Student Services staff for supporting this project.

\section{References}

1. S. Fisher, and B. Hood, "The stress of the transition to university: a longitudinal study of psychological disturbance, absent-mindedness and vulnerability to homesickness," $J$ Psychol., vol. 78 (pt 4), pp. 425-441, 1987. 
2. A. Hutchins, "Are universities doing enough to support mental health? - Macleans.ca," MacLean's, 2017. [Online]. Available: https://www.macleans.ca/education/depth-of-despair/.

3. Q. Golsteyn, and D. Nino, "An Analysis on the State of Wellness of Engineering Undergraduate Students," in Proc. CEEA Canadian Engineering Education Conf., CEEA18, (Vancouver, BC; 3-6 June 2018), 4 pp., 2018.

4. "Mental health: a state of well-being," WHO, 2014 [Online]. Available: http://origin.who.int/features/factfiles/mental_health/en/.

5. R. Dodge, A. P. Daly, J. L. Huyton, and L. Sanders, "The challenge of defining wellbeing," International Journal of Wellbeing, vol. 2, no. 3, pp. 222-235, 2012.

6. P. M. Ostafichuk, C. P. Jaeger, J. Nakane, S. Nesbit, N. Ellis, and J. Sibley, "Redesigning the UBC first-year introduction to Engineering: successes and challenges," in Proc. CEEA Canadian Engineering Education Conf., CEEA16, (Halifax, NS; 19-22 June 2016), 8 pp., 2016.

7. A. W. Ulwick, "Turn Customer Input into Innovation," Harvard Business Review, vol. 80, no. 1, pp. 91-98, 2002.

8. S. L. Stewart-Brown, A. Tennant, R. Tennant, S. Platt, J. Parkinson, and S. Weich, "Internal construct validity of the Warwick-Edinburgh Mental Well-being Scale (WEMWBS): a Rasch analysis using data from the Scottish Health Education Population Survey," Health and Quality of Life Outcomes, vol. 7, no. 15, 2009.

9. J. Crocker, "The costs of seeking self-esteem.," Journal of Societal Issues, vol. 58, no. 3, pp. 597-615, 2002.

10. "Piazza Homepage" [Online]. Available: https://piazza.com/.

11. J. Earwaker, Helping and Supporting Students. Rethinking the Issues. London, UK: Open University Press, 1992, 153 pp. \{ISBN: 0-335-15665-7\}

\section{A.OVERVIEW OF FACTORS}

Below is a list the top 5 factors per category. These factors are based from the "successes" and "challenges" activity conducted during the 2018-2019 academic year. The opportunity score is indicated in parentheses.

\section{A.1.Academic}

1. Overcoming the fear of failure (1.61)
2. Having enough time to study for midterms/finals (1.50)

3. Handling the course load (1.48)

4. Being more productive (1.46)

5. Avoiding procrastination (1.41)

\section{A.2.Wellbeing}

6. Feeling positive throughout the year (1.57)

7. Getting enough sleep (1.57)

8. Dealing with feeling overwhelmed (1.40)

9. Avoiding burnout (1.37)

10. Staying motivated (1.35)

\section{A.3.Social}

11. Having time for social activities and maintaining relationships (1.24)

12. Making friends (1.17)

13. Having a close friend (1.00)

14. Having opportunities to socialize with others (0.97)

15. Asking for help (0.87)

\section{A.4.Workload}

16. Managing time (1.37)

17. Prioritizing (1.24)

18. Balancing commitments (1.22)

19. Overcoming disappointments (1.14)

20. Handling the ambiguity of university (1.06)

\section{A.5.Lifestyle}

21. Finding a community on campus (1.13)

22. Having the ability to try new things (1.00)

23. Maintaining personal interests $(0.91)$

24. Joining a student club (0.67)

25. Joining an engineering design team $(0.52)$

\section{A.6.Cultural integration}

26. Speaking English (0.71)

27. Adapting to a new culture (0.68)

28. Having an opportunity to continue to express and celebrate your traditions and culture (0.59)

29. Having an opportunity to experience Canadian culture $(0.55)$ 